\title{
Prediction of Asbestos Cement Water Pipe Aging and Pipe Prioritization using Monte Carlo Simulation
}

\author{
Wonsiri Punurai ${ }^{1, a, *}$ and Paul Davis ${ }^{2, b}$ \\ 1 Department of Civil and Environmental Engineering, Mahidol University, Nakorn pathom, Thailand \\ 2 CSIRO Urban Water Research, 37 Graham Road, Highett, Victoria 3190, Australia \\ E-mail: aWonsiri.Pun@mahidol.ac.th (Corresponding author), bPaul.Davis@csiro.au
}

\begin{abstract}
For buried Asbestos cement (AC) pipes in service, internal and external surface degradation occur by dissolution or leaching of cement-based components leading to loss of pipe strength. Since water quality and soil environment cannot be completely specified along a pipeline, a management methodology for $\mathrm{AC}$ water pipelines is required to estimate the probability of pipe failure as ageing proceeds. The paper describes the technique and its application to experimental data, which illustrates in three parts. First, the degradation rates in AC pipes are computed from 360 aggregated independent pipe segments residual strength test data taken from different pipe diameter sizes used in various water utilities locations in Thailand. Second, the predictions of service lifetime for AC pipes are estimated using Monte Carlo simulation in conjunction with the physical failure state formulations. Output from the simulation provides a number of failures recorded over time, which then allows the economic analysis for optimal pipe replacement scheduling. All is described in the third part. The end results can be used for water utilities to allocate government funds for future pipe maintenance activities.
\end{abstract}

Keywords: Water pipe aging, probability of failure, pipe maintenance, cement-based materials, strength, Monte Carlo method.

ENGINEERING JOURNAL Volume 21 Issue 2

Received 14 April 2016

Accepted 19 August 2016

Published 31 March 2017

Online at http://www.engj.org/

DOI:10.4186/ej.2017.21.2.1 


\section{Introduction}

Asbestos cement is made by combining asbestos fibers with Portland cement. The fibers can account for between 10 and $70 \%$ of the total material, however asbestos cement fibers typically comprised less than $20 \%$ [1]. Compositions of each of Portland cement are shown in Table 1. Asbestos cement pipe is generally produced using cement types I and II, while type V is used in special situations [2]. However cement type I is no longer used to produce asbestos cement pipe in the United States. The constituent oxides undergo a series of hydration reactions to produce the phases which provide strength to the final product. The main phase composition of the different cement types is shown at the bottom of Table 1, however over one hundred different compounds and phases have been identified and many more may exist due to solid solution possibilities [3]. It can be seen that while the initial oxide composition of the different cement types are quite similar the resulting calcium phase compositions vary greatly, it is this variation that provides the varying properties of the cement types.

Table 1. Composition of the Portland cement varieties [2].

\begin{tabular}{llllll}
\hline Oxide & Type I & Type II & Type III & Type IV & Type V \\
\hline $\mathrm{SiO}_{2}, \%$ Silicon dioxide (silica) & 21.3 & 22.3 & 20.4 & 24.3 & 25.0 \\
$\mathrm{AL}_{2} \mathrm{O}_{3}, \%$ Aluminium oxide (alumina) & 6.0 & 4.7 & 5.9 & 4.3 & 3.4 \\
$\mathrm{Fe}_{2} \mathrm{O}_{3}, \%$ Iron oxide & 2.7 & 4.3 & 3.1 & 4.1 & 2.8 \\
$\mathrm{CaO}, \%$ Calcium oxide (lime) & 63.2 & 63.1 & 64.3 & 62.2 & 64.1 \\
$\mathrm{MgO}, \%$ Magnesium oxide & 2.9 & 2.5 & 2.0 & 1.8 & 1.1 \\
$\mathrm{SO}_{3}, \%$ Sulphate & 1.8 & 1.7 & 2.3 & 1.9 & 1.6 \\
$\mathrm{Loss}, \%$ & 1.3 & 0.8 & 1.2 & 0.9 & 0.9 \\
Insoluble, \% & 0.2 & 0.1 & 0.2 & 0.2 & 0.2 \\
$\mathrm{C}_{3} \mathrm{~S}$ & $45 \%$ & $44 \%$ & $53 \%$ & $28 \%$ & $38 \%$ \\
$\mathrm{C}_{2} \mathrm{~S}$ & $27 \%$ & $31 \%$ & $19 \%$ & $49 \%$ & $43 \%$ \\
$\mathrm{C}_{3} \mathrm{~A}$ & $11 \%$ & $5 \%$ & $11 \%$ & $4 \%$ & $4 \%$ \\
$\mathrm{C}_{4} \mathrm{AF}$ & $8 \%$ & $13 \%$ & $9 \%$ & $12 \%$ & $9 \%$ \\
\hline
\end{tabular}

Asbestos cement pipes were manufactured by three methods [4]. The Sutton Method was the first used in 1928. The Sutton process rolled sheets of cemented asbestos onto collapsible mandrels, where they were then wrapped in calico and wound with wire cable to increase compaction while they cured in water and air for 14 days in each environment. Pipe manufactured by this method proved to be inadequate as material became laminated between layers and initially these pipes were not dip coat allowing leaching to occur. Adolfo Mazza developed a machine to create asbestos cement pipe in 1916. Mazza's machine fed asbestos sheet through a cement/asbestos slurry bath to impregnate cement into the sheet, which was then fed over suction rollers to remove excess water. The sheet was then rolled onto a mandrel until the required thickness was achieved. During the rolling stage the sheet was placed under mechanical pressure by the roller to compact the material. The pipe was separated from the mandrel with an air jet leaving a seamless internal faced. The pipe was then rolled through a steam chamber to achieve initial hardening before water curing for 28 days. This method produced superior pipe to the Sutton Method. Asbestos cement pipe manufacture was further advanced with the introduction of autoclave curing of and the addition of fine ground silica powder in 1954. Autoclaving and addition of silica increased the pipes mechanical strength and allowed the pipe to be freed from the mandrel without need of the air jet used in the Mazza method. The pipe was separated from the mandrel using a strong electrostatic charge is introduced, producing steam around the pipe, freeing it from the mandrel, further compressing the pipe and inducing initial strengthening. The pipe was then steam cured for 24 hours at 2 atmospheres and further water cured for 28 days. In Italy, approximately 90 years ago, Asbestos cement pipe was developed to withstand the pressures required to pump seawater for a street flushing program [5]. Since this time the number of pipes in service rose almost exponentially from initial development to the seventies when an estimated 2.4 million kilometers of pipe in service worldwide. Asbestos cement pipes made up approximately $15 \%$ of North American water pipes in 1992 [6], although its use in western countries curtailed in the 70's due to the 
increased understanding of the health risks associated with inhalation of asbestos fibers and the related litigation. The rapid spread of asbestos cement pipe was due to its many advantages it provided:

- Asbestos cement pipe is resistant to corrosion, both internally and externally. This resistance has been demonstrated in tests run by the US Bureau of Standards on buried samples and by the US Bureau of Mines through tests conducted using corrosive mine-drainage water.

- Asbestos cement pipe is able to withstand the high internal pressures imposed by water hammer and shock earth loads from earthquakes, whereas standard cement pipe cannot.

- Asbestos cement pipe has contributed to high water quality. Manufacturers of the pipe pioneered the use of rubber ring joints - joints containing no jute, which offered a focal point for bacterial growth. Asbestos cement pipe does not rust and cause discoloration of the water.

- Asbestos cement pipe is lightweight, and easy for contractors to install. These qualities result in lower installation costs.

- Asbestos cement pipe has a permanently smooth interior wall, so pumping costs remain low.

According to AWWA (2001), water is the most capital intensive of all utility services, owing to the high cost of pipelines. In addition to being buried underground, many pipes were originally installed and paid for by previous generations. As these pipes are ageing and nearing the end of their useful life, they need to be replaced; the cost to manage is becoming our burden. However, it is not cost-effective to replace a pipe before, or even after, the first break. As such a proactive approach to pipe asset management is crucial in determining the optimal time to replace a pipe. A state of the art reveals direct and indirect sensing techniques for buried sewer inspection [7]. However, all current approaches only provide the collection of information about pipe anomalies and pipe condition. Analysis of this information and ultimately transformation into knowledge, leading to effective decision about renewal is still required [8-9]. The purpose of this paper describes the technique and its application to experimental data which differs from the previous studies. The approach makes decision-making transparent by including the physical failure state formulations in conjunction with Monte-Carlo simulations to provide a number of failures recorded over time for any AC pipe diameter and pressure class rating, thus aiding the water utility manager in the prediction of service life and in the prioritization of pipes for replacement in water utility asset management based on its expected failure rate.

\section{Failure of Asbestos Cement Pipes}

Asbestos cement pipes failures occur in two ways, circumferential failure due mechanical loading, and longitudinal failures which occur as a result of material corrosion [10].The longitudinal failures occur in $80 \%$ of burst field pipes [11]. Mechanical failure is generally a result of poor trench conditions and locating of the pipe (i.e. under heavy loads such as traffic loads Material corrosion is a result of both internal and external environments and their degree of aggressiveness to the cement matrix [12]. Unlike metallic pipes where corrosion takes place by electrochemical reactions corrosion in asbestos cement pipe occurs by dissolution or leaching of components. Asbestos cement corrosion is governed by the solubility and kinetic properties of the pipe system. Corrosion occurs primarily due to leaching of calcium hydroxide from the cement matrix into the surrounding environment. The weakening of the cement matrix also allows the escape of asbestos fibers into the water distribution network. Drilling and tapping activities can greatly influence the amount of asbestos cement fibers released [13].

Corrosion of asbestos cement pipe is often quantified using the phenolphthalein test. The phenolphthalein test uses a through wall thickness test cylindrical specimen which is stained with phenolphthalein solution $(0.01 \%$ solution). A sample of new or un-corroded pipe will turn pink as the cement is alkaline in nature due to the calcium hydroxide. Areas in which leaching has occurred will show no color change, as do areas in which calcium carbonate has precipitated [14-16].

\subsection{Internal Corrosion}

Internal corrosion occurs in soft water and acidic. Calcium hydroxide (free lime) is leached out into the water from the cement matrix; initially calcium hydroxide is removed as free lime; however when the free lime is exhausted hydrated calcium silicates decompose to calcium hydroxide. The calcium silicates are the primary strength giving phases in the cement matrix and their loss causes softening of the pipe and fiber 
release. An acidic environment assists dissolution. The higher the amount of calcium hydroxide present in the asbestos cement pipe the higher the degree of corrosion will be observed. The Aggressiveness Index (AI) of water being transported has a strong relationship to the occurrence of internal corrosion [17]. This basic relationship between AI and the aggressiveness of transported water to AC pipe was defined by Eq. (1).

$$
A I=p H+\log (A \times H)
$$

where $\mathrm{AI}=$ Aggressiveness index, $\mathrm{pH}=\mathrm{pH}$ of the water, $\mathrm{A}=$ total alkalinity as $\mathrm{CaCO}_{3}(\mathrm{mg} / \mathrm{L}), \mathrm{H}=$ calcium hardness $\mathrm{CaCO}_{3}(\mathrm{mg} / \mathrm{L})$. Water with an AI equal to or exceeding 12 is considered as nonaggressive. Water with an AI between 10 and 12 is considered as moderately aggressive. Water with an AI below 10 is considered as highly aggressive.

Buelow et al. (1980) writes that while AI has been widely used, AI alone is not always sufficient for the prediction of corrosion of asbestos cement pipe and will often predict a greater degree of corrosion as it does not take into account protective chemicals in the water supply other than calcium. Four other elements that can form useful coatings are iron, zinc, manganese and silica. The likelihood of these elements forming a beneficial coating from these elements is dependent mainly on their concentration and $\mathrm{pH}$. Schock and Buelow (1981) goes on to say that calcium, iron, manganese and silica provide protection against corrosion by precipitating onto the surface of the pipe and inhibiting dissolution of both calcium hydroxide and release of asbestos fibers, however not all precipitated layers do both some binding only the asbestos fibers to the pipe while still allowing calcium dissolution. The quality of the transported water must be maintained to prevent dissolution of the layer. Calcium dissolved from the pipe can protects the pipe by saturating the water, preventing further dissolution, and by precipitating onto the pipe as calcium carbonate. Precipitation of calcium carbonate is a common process and generally known as carbonation. The calcium carbonate can also dissolve back into the water but is less soluble than calcium hydroxide. However carbonation is known to cause embrittlement of the pipe, the extent of carbonation is dependent on pipe permeability and curing [18].

Use of the more complex Saturation Index (SI) may be able to overcome the many limitations of the Aggressiveness Index. SI is able to incorporate the solubility of pipe components and the possible protective species in the water. The saturation index uses bulk-solution chemical parameters and solid solubility reactions. The thermodynamic state of saturation was quantified by SI, defined as the logarithm of the ion activity product (IAP) over the solubility product constant $\left(\mathrm{K}_{\mathrm{so}}\right.$ or $\left.\mathrm{K}_{\mathrm{sp}}\right)$.

$$
S I=\log \left(\frac{I A P}{K_{s o}}\right)
$$

The solubility product is temperature dependent and can be found in literature (or calculated using Gibbs free energy), however values vary between sources. The IAP is calculated for specific systems by analyzing the actual ion content. e.g. for the following reaction [19]:

IAP is calculated using

$$
\mathrm{CaSO}_{4(s)} \leftrightarrow \mathrm{Ca}^{2+}{ }_{(a q)}+\mathrm{SO}_{4}^{2-}{ }_{(a q)}
$$

$$
L A P=\gamma_{\mathrm{Ca}^{2+}}\left[\mathrm{Ca}^{2+}\right]_{\mathrm{SO}_{4}^{2-}}\left[\mathrm{SO}_{4}^{2-}\right]
$$

where $\left[\mathrm{Ca}^{2+}\right]$ is the calcium ion concentration and $\gamma_{\mathrm{Ca}^{2+}}$ is the calcium activity coefficient. When IAP $>$ $\mathrm{K}_{\text {so }}$, SI $>0$, active deposition thermodynamically favored, when IAP $<\mathrm{K}_{\text {so }}$, SI $<0$, dissolution is thermodynamically favored, and when IAP $=\mathrm{K}_{\mathrm{so}}$, $\mathrm{SI}=0$, the system is said to be in equilibrium.

Varying the $\mathrm{pH}$ of the system will alter the ion concentrations and so by changing $\mathrm{pH}$ the system can move from leaching to deposition and reverse, see Fig. 1 and Table 2. In Fig. 1, it can be seen that only $\mathrm{Zn}_{5}\left(\mathrm{CO}_{3}\right)_{2}(\mathrm{OH})_{6}$ has a SI that moves above 0 above $\mathrm{pH}$ 8, while $\mathrm{ZnCO}_{3}$ reaches $\mathrm{SI}=0$ at $\mathrm{pH} 8.5$, all other species have negative $\mathrm{SI}$ in and so would remain in solution. 
Table 2. Model system composition, @ 25ํ․ m [19].

\begin{tabular}{|c|c|c|c|c|c|c|c|c|c|}
\hline \multicolumn{2}{|c|}{ Calcium } & \multicolumn{2}{|c|}{ Total Carbonate } & \multirow[b]{2}{*}{$\begin{array}{c}\mathrm{Mg} \\
\mathrm{mg} / \mathrm{L}\end{array}$} & \multirow[b]{2}{*}{$\begin{array}{c}\mathrm{Na} \\
\mathrm{mg} / \mathrm{L}\end{array}$} & \multirow[b]{2}{*}{$\begin{array}{c}\mathrm{Cl} \\
\mathrm{mg} / \mathrm{L}\end{array}$} & \multirow[b]{2}{*}{$\begin{array}{c}\mathrm{Zn} \\
\mathrm{mg} / \mathrm{L}\end{array}$} & \multirow[b]{2}{*}{$\begin{array}{c}\mathrm{Fe} \\
\mathrm{mg} / \mathrm{L}\end{array}$} & \multirow[b]{2}{*}{$\begin{array}{c}\mathrm{PO}_{4} \\
\mathrm{mg} / \mathrm{L}\end{array}$} \\
\hline $\begin{array}{c}\mathrm{mg} / \mathrm{L} \text { as } \\
\mathrm{Ca}\end{array}$ & $\begin{array}{c}\mathrm{mg} / \mathrm{L} \text { as } \\
\mathrm{CaCO}_{3}\end{array}$ & $\begin{array}{c}\mathrm{mg} / \mathrm{L} \text { as } \\
\mathrm{Ca}\end{array}$ & $\begin{array}{c}\mathrm{mg} / \mathrm{L} \text { as } \\
\mathrm{CaCO}_{3}\end{array}$ & & & & & & \\
\hline 0.4 & 1.0 & 0.6 & 1.0 & 0.1 & 5 & $4-9$ & 0.5 & 0 & 0 \\
\hline
\end{tabular}

Saturation Index

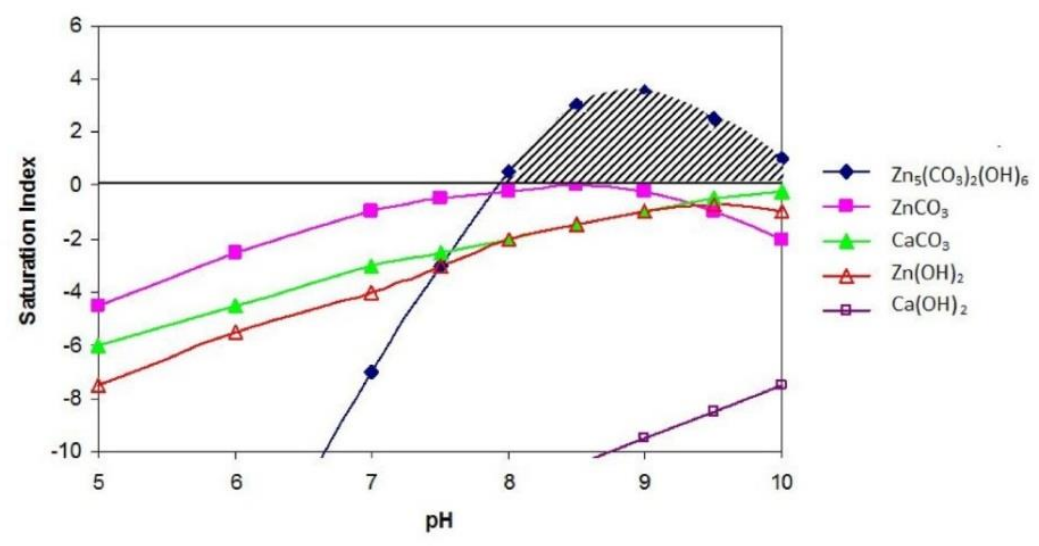

Fig. 1. Saturation index diagram for model system [19].

\subsection{External Corrosion}

The external corrosion occurs in 'soft' (low in calcium carbonate), acidic and sulphate soils [20]. External corrosion occurs in two ways, calcium leaching, into surrounding water as with internal corrosion, and sulphate reaction with silica compounds to form weaker and larger compounds which result in swelling of the cement matrix [21]. St John et al. (1998) states that $\mathrm{pH}$ must be below 7 for significant external attack to occur. Asbestos cement pipes which undergo pure sulphate attack obtain a characteristic whitish appearance. Sulphate attack occurs in sulphate rich environments, but does not occur until solid sulphate salts are in solution. The sulphate solution reacts with the asbestos cement in three ways:

1. Gypsum forming: A combination of sulphate and free lime (calcium hydrate) liberated during the hydration of cement to form calcium sulphate (gypsum).

2. Ettringite forming: A combination of sulphate and hydrated calcium aluminate or monosulphate to form calcium sulphoaluminate (ettringite).

3. Thaumasite forming: A combination of sulphate and calcium silicates to form thaumasite.

Both ettringite and thaumasite have very similar x-ray diffraction patterns which can be differentiated with only the most sophisticated equipment. From this it can be assumed that in past literature where ettringite formation is named a product of sulphate attack, both ettringite and thaumasite may have been present [22].

Matti and Al-Adeeb (1985) found that the gypsum and ettringite formed by these reactions occupy considerably more volume (123\% to 224\%) than the original solids they replace. The formation of these compounds causes swelling, which can ultimately lead to the expansion and destruction of the cementitious portion of the pipe. The extent of reaction is dependent upon the type of sulphate salts reacting (sodium, magnesium or calcium). The effect of sulphate concentration may be mitigated by the presence of high concentrations of chloride. The effects of calcium leaching, in both internal and external corrosion, are summarized by Jarvis (1998). Calcium leached from the cement matrix is initially removed from the free lime phase and then from the calcium silicates when this source is exhausted. Ellis et al. (1998) found that 
sand bedding of ductile iron pipes reduced external corrosion, this may also true for asbestos cement pipe, suggesting that installation practices should also be considered for their effect on external corrosion [23].

\subsection{Physical Probabilistic Failure Model}

As indicated earlier that variations in $\mathrm{pH}$ and sulphate content at the pipe/environment interface can influence the rate of AC pipe degradation; Davis et al. (2008) developed a physical probabilistic model of degradation in $\mathrm{AC}$ water pipes due to the combination of static internal pressure and/or external vertical (crushing) loads. A description of the basic mechanism by which pipes deteriorate and finally fail was presented and the effect of bending loads was not included. This model has been implemented within the PARMS Risk software tool and requires a number of input parameters [24-26]. The model is described below:

(1) Uncertainty in degradation exists and this uncertainty can be described by the two-parameter Weibull distribution function, defined as

$$
F\left(S_{R}\right)=1-\exp \left\{-\left(\frac{S_{R}}{\alpha}\right)^{\eta}\right\}
$$

where $F\left(S_{R}\right)$ is the probability that the measured degradation rate is less than a particular value $S_{R}$, and $\alpha$ and $\eta$ are the scale and shape parameter of the Weibull distribution. Following Davies et al. (2008), an empirical distribution function can be estimated from raw reduced indirect tensile strength $S_{f}$ data tested on small cylindrical core samples taken from the AC pipes in the circumferential direction (Fig. 2). The estimation using Weibull function is appropriate when a straight line can be used to represent data of the plot of $\ln \left[-\ln \left\{1-F\left(S_{R}\right)\right\}\right]$ versus $\ln \left(S_{R}\right)$ with a regression coefficient of 0.8 or more. It should be noted here that the measured degradation rate $S_{\mathrm{R}}$ and residual tensile strength $S_{f}$ are measured in MPa and are related by $S_{f}=S_{0}-(A g e) / S_{R}$ where $S_{0}$ is the original as-produced undegraded tensile strength and Age is time since the installation measured in years.
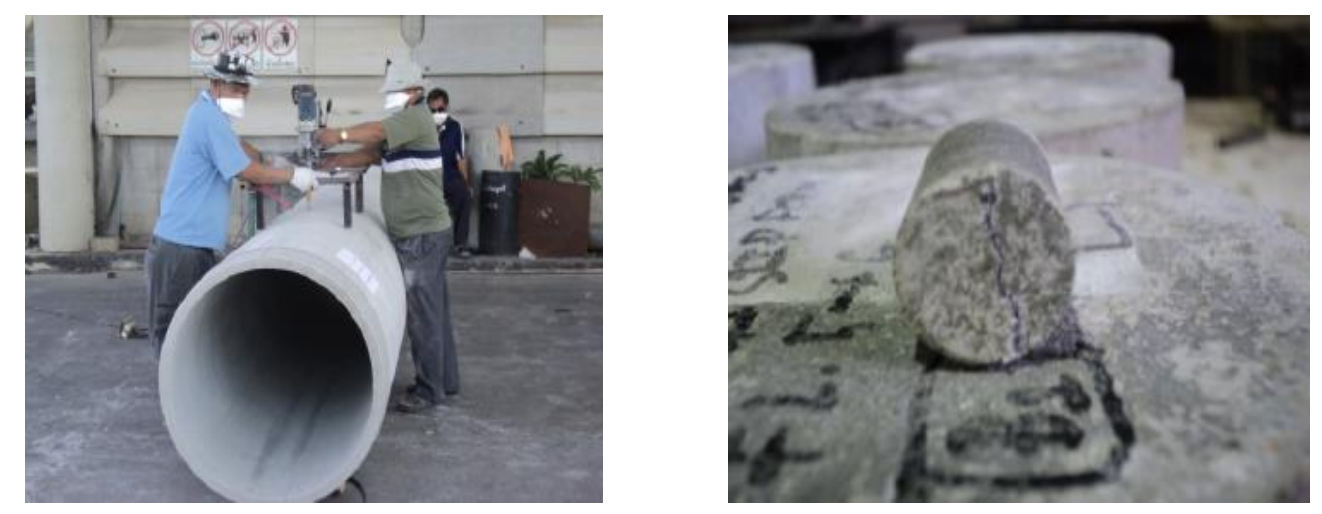

Fig. 2. Residual strength measurements using core samples [27].

(2) Pipe failure is deemed to have occurred when the failure criterion inequality given by Eq. (6) is true.

$$
\frac{p_{\max }}{p_{c}} \geq 1-\left(\frac{W}{W_{c}}\right)^{2}
$$

In Eq. (6), $p_{\max }$ is the maximum applied internal pressure (in MPa); pc is the critical pressure that would cause failure in the absence of any external loading; $W$ is the actual applied external vertical loads (in $\mathrm{N} / \mathrm{m}$ ) and $W_{c}$ is the external vertical loads that would cause failure with no internal pressure (in $\mathrm{N} / \mathrm{m}$ ). The critical pressure pc and the critical external loads $W_{c}$ are calculated via net section collapse and can be written in terms of the residual tensile strength $S_{f}$ of the pipe wall as:

$$
p_{c}=\frac{2 S_{f} b_{f}}{D-b_{0}}, \quad W_{c}=\frac{1.048 F_{m} S_{f} b_{f}^{2}}{D-b_{0}}
$$


where $b_{0}$ is the original wall thickness (in $\mathrm{m}$ ); $b_{f}$ is the reduced wall thickness (in $\mathrm{m}$ ); $D$ is the outside pipe diameter (in $\mathrm{m}$ ); $F_{m}$ is a bedding factor which is equal to 1.5 for non-gravel beds and other soil surrounds. For a buried pipe in service, bf can be computed from a linear rate of thickness loss given by $b_{f}=b_{0}-\left[\right.$ Age $\left.\times\left(b_{r} / 1000\right)\right]$ where $b_{r}$ is the wall thickness erosion rate (in $\mathrm{mm} /$ year).

The applied external load $W$ comprises an earth load from the surrounding soil $P_{e}$ (in $\mathrm{MPa}$ ) and a live surface load Ps from the overhead traffic (in $\mathrm{kPa}$ ).

$$
W=\left(P_{e}+P_{s}\right)(D)
$$

In Eq. (8), $P_{e}$ can be written in terms of the pressure concentration factor $\mathrm{C} 1$, soil consolidation coefficient $\mathrm{Ft}$, soil unit weight $\gamma$ (in $\mathrm{kN} / \mathrm{m} 3$ ) and burial depth $\mathrm{H}$ (in $\mathrm{m}$ ) as:

$$
P_{e}=\left[\frac{1}{C_{1}}+\left(1-\frac{1}{C_{1}}\right) e^{\frac{-A_{g e}}{F_{t}}}\right] \times\left(C_{1} \times \gamma \times H\right)
$$

\subsection{Monte Carlo Simulations of AC-Pipe Lifetimes}

Having estimated the Weibull probability distribution and the corresponding predicted service lifetime from Eq. (6), Monte Carlo simulation can now be used to generate failures for AC pipes with details required as outlined below:

(1) The Monte Carlo simulation samples failure times to predict lifetime of simulated set of pipes. Each pipe is assigned a maximum strength loss rate and a maximum erosion rate based on an erosion rate probability distribution. The strength loss rate and erosion rate probability distributions are developed based on a series of residual strength and wall thickness measurements taken during condition assessments using core samples. It is assumed that the results of condition assessment are applicable to a single pipe.

(2) Pipe lifetime is the age at which the limit state Eq. (6) becomes true. Pipe lifetime is determined iteratively by calculating the limit state for each year of age until failure occurs.

(3) Pipe failure frequency is determined by dividing the number of pipes that fail in any years by the total number of simulated pipes. The parameters listed below in Table 3 are those which are required to be added to the Monte Carlo simulation to adjust the model to the examined pipe. These input parameters have been limited as much as possible to only those parameters that are easily obtained. For others those are either generic or difficult to obtain and so default values found from the literature [28-30] have been applied.

Table 3. Physical Probabilistic failure model required input parameters.

\begin{tabular}{lll}
\hline Parameters (units) & Symbol & Value \\
\hline Original wall thickness $(\mathrm{m})$ & $b_{0}$ & 0.045 \\
Outside diameter $(\mathrm{m})$ & $D$ & 1 \\
Maximum internal pressure (MPa) & $p_{\max }$ & 0.2 \\
Burial depth $(\mathrm{m})$ & $H$ & $1.2-1.5$ \\
Soil unit weight of sandy, clayey soils $\left(\mathrm{kN} / \mathrm{m}^{3}\right)$ & $\gamma$ & 18 \\
Pressure concentration factor (unitless) & $C_{1}$ & 1.6 \\
Surface pressure for single lane traffic loading (kPa) & $P_{s}$ & 16 \\
Bedding factor for non-gravel beds and other soil surrounds (unitless) & $F_{m}$ & 1.5 \\
Soil consolidation coefficient for clay soil above ground water (unitless) & $F_{t}$ & 400 \\
\hline
\end{tabular}

\section{Test Results and Discussions}

The above approach was applied to the 360 aggregated independent pipe segments residual strength test data (40 semi-aged and aged pairs) taken for 9 different pipe diameter sizes and pressure ratings used in various Thai water utilities locations obtained from The International Water Pipe company limited database. 
The extent of this study was limited to inventory and data from the 2000 fiscal year due to insufficient inventory records for previous years. In addition, the length and the age of pipes in the system each year also varied.

\subsection{Probability Distribution of Degradation in AC Water Pipes}

Example Weibull plots of probability density function strength loss rates and example Weibull plots for degradation rates of AC1000-10, AC500-15, and AC100-20 pipes are shown in Figs. 3, 4, and 5. It should be noted here that the $\mathrm{AC}$ water pipe names reported in these plots are designated by their diameter sizes and their minimum required strengths at the final age. For example, AC1000-10 is the asbestos cement water pipe that has a pipe diameter of $1000 \mathrm{~mm}$, and can withstand a test pressure of 10 bars during useful life period. For this particular pipeline, the expected strength loss rate, read from Fig. 3, is $0.214 \mathrm{MPa}$ per year and the standard deviation is $0.104 \mathrm{MPa}$ per year. A best-fit straight line in Weibull plots of degradation rate also indicate the applicability of the Weibull distribution acceptance of measured degradation rates for all pipe sizes. Considering the relationship shown in Eq. (5), the gradient and intercepts of the straight line as illustrated in Fig. 3 allows the Weibull scale and shape parameters to be estimated and reported together with strength loss rate values. Following the procedure outlined in [27], the scale and shape parameters for different pipe sizes were calculated and shown in Table 4.
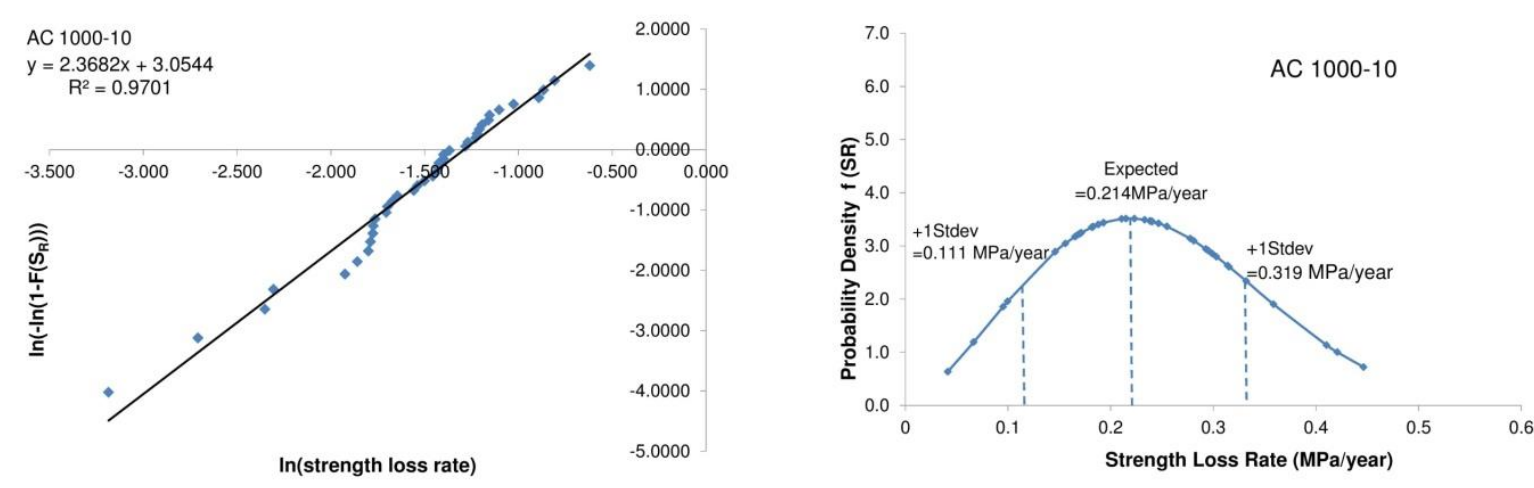

Fig. 3. Weibull plots for degradation rate for and probability density function strength loss rate in 1000 $\mathrm{mm}$ diameter $\mathrm{AC}$ water pipe.
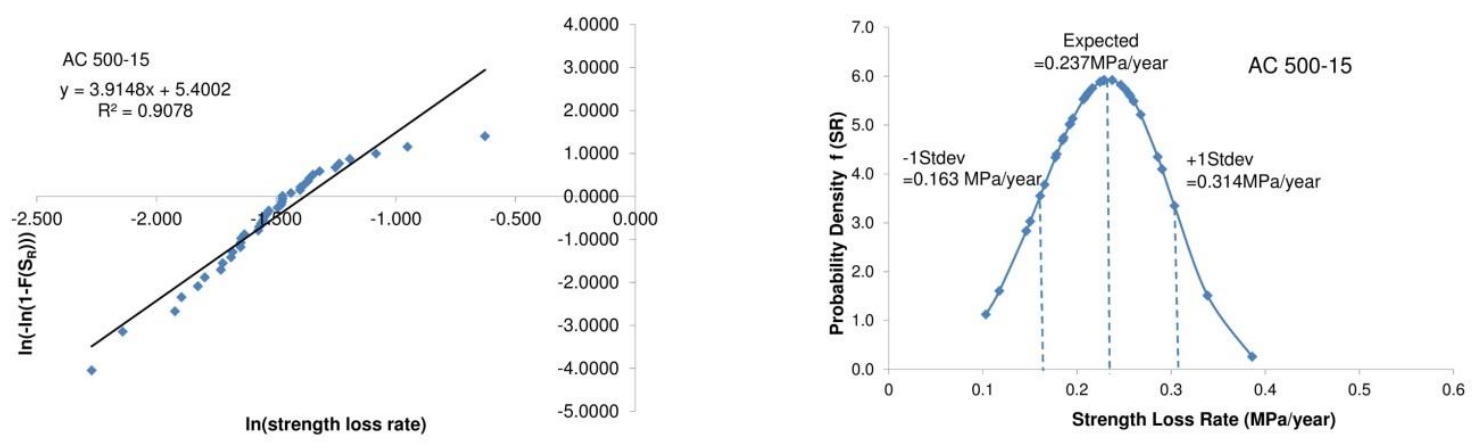

Fig. 4. Weibull plots for degradation rate for and probability density function strength loss rate in $500 \mathrm{~mm}$ diameter $\mathrm{AC}$ water pipe. 

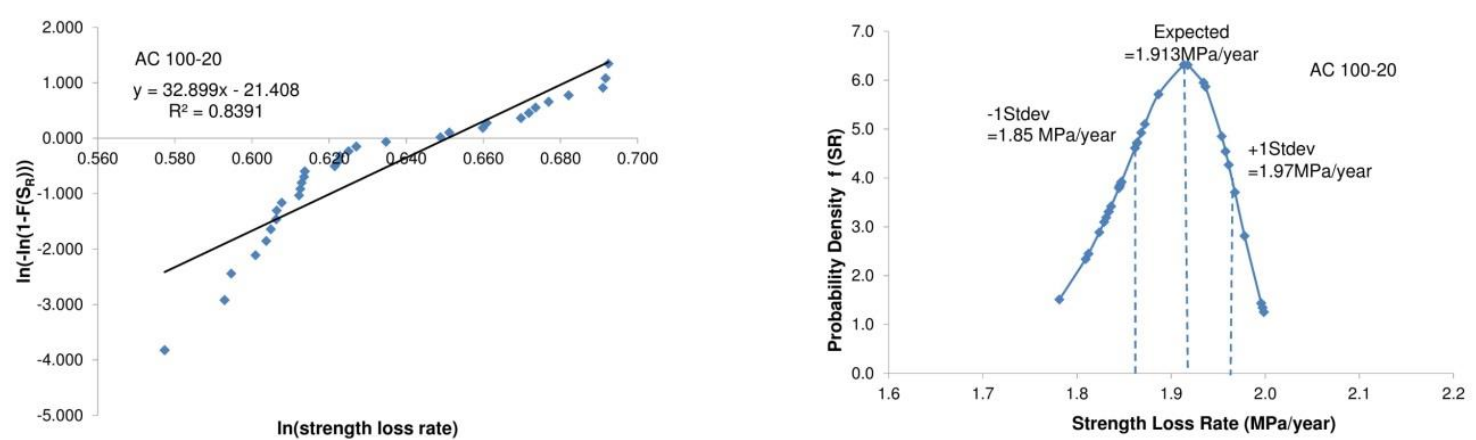

Fig. 5. Weibull plots for degradation rate for and probability density function strength loss rate in $100 \mathrm{~mm}$ diameter AC water pipe.

Table 4. Weibull scale and shape parameters determined from various diameter pipes.

\begin{tabular}{lcccccccccc}
\hline \multirow{2}{*}{ Attribute } & \multicolumn{10}{c}{ Diameter $(D, \mathrm{~mm})$} \\
\cline { 2 - 12 } & 100 & 150 & 200 & 250 & 300 & 400 & 500 & 600 & 800 & 1000 \\
\hline Wall thickness $\left(b_{0}, \mathrm{~mm}\right)$ & 11.5 & 14.5 & 18.5 & 20.5 & 24 & 32 & 32 & 37 & 46 & 45.5 \\
Installation (year) & 2002 & 2002 & 2002 & 2001 & 2002 & 2002 & 2001 & 2001 & 2001 & 2001 \\
$\begin{array}{l}\text { Maximum Internal } \\
\text { pressure }(\mathrm{MPa})\end{array}$ & 0.3 & 0.3 & 0.3 & 0.3 & 0.3 & 0.3 & 0.2 & 0.2 & 0.2 & 0.2 \\
$\begin{array}{l}\text { Test pressure during } \\
\text { useful life period }(\mathrm{MPa})\end{array}$ & 20 & 20 & 20 & 20 & 20 & 20 & 15 & 15 & 15 & 10 \\
$\begin{array}{l}\text { Scale parameter }(\alpha) \\
\text { Shape parameter }(\eta)\end{array}$ & 1.92 & 0.93 & 1.53 & 0.29 & 0.41 & 0.06 & 0.25 & 0.31 & 0.33 & 0.28 \\
\hline
\end{tabular}

\subsection{Monte Carlo Simulations of AC Pipe Lifetimes}

Having estimated the Weibull probability distribution for measured degradation rates, Monte Carlo simulation was used to predict a number of service lifetimes in different sized AC pipes subjected to the combined internal pressure and external loading. Using the variables detailed shown in Table 3 and 4, The Monte Carlo simulation sampled failure times by repeatedly generating random numbers for degradation rate, e.g. 10,000, and using these to predict the time to failure for a set of trials. Pipe lifetime was determined iteratively by calculating the limit state, Eq. (6), for each year of age until failure occurs. Pipe failure frequency (expressed as failures per year) was determined by dividing the number of pipes that fail in any years by the total number of simulated pipes. In this study, the total number of random simulated data is set to be 10,000 .

Plotting the pipe failure frequency of each pipe size against the time from the installation period, a failure frequency distribution curve was produced, as illustrated in Fig. 6 for AC100-20 AC300-20, AC40020and AC1000-10 pipes. It was observed from the shape of the curve for all pipes that the failure frequency was low towards the beginning of the curve, increased in the middle, and decreased toward the end. This suggests that the AC pipes have a high tendency to fail during the useful life period. The pipe failure distribution curve also showed the three phases of pipe failure: pessimistic life period, expected life period and the optimistic life period. The first phase, known as the pessimistic life period, is characterized by the highest failure frequency rate that shows up early in use. The failures occur in this period immediately after the installation as a consequence of faulty installations and/or problems with pipe materials supplied by external supplier. Once repaired, these failures usually do not happen again. The second phase, or the expected life period, is characterized at the 70 percent of highest failure frequency rate/ or depicted at the maximum value of failure frequency -1 standard deviation after the pessimistic lifetime period. The pipe failures in this period come about as a result of random phenomena such as extreme heavy loading, earth 
moving, or third party interference. The third phase is the optimistic life period and is characterized at the 30 percent of highest frequency failure rate/or at the age at which the failure frequency value is limited to the value of +1 standard deviation after the expected life period. The consequences of failure in this period are low but are related to the risk aversion level of the particular water authority concerned. Analysis of the three distinct failure phases shown in Fig. 6 and for all other pipe sizes is summarized in Table 5.
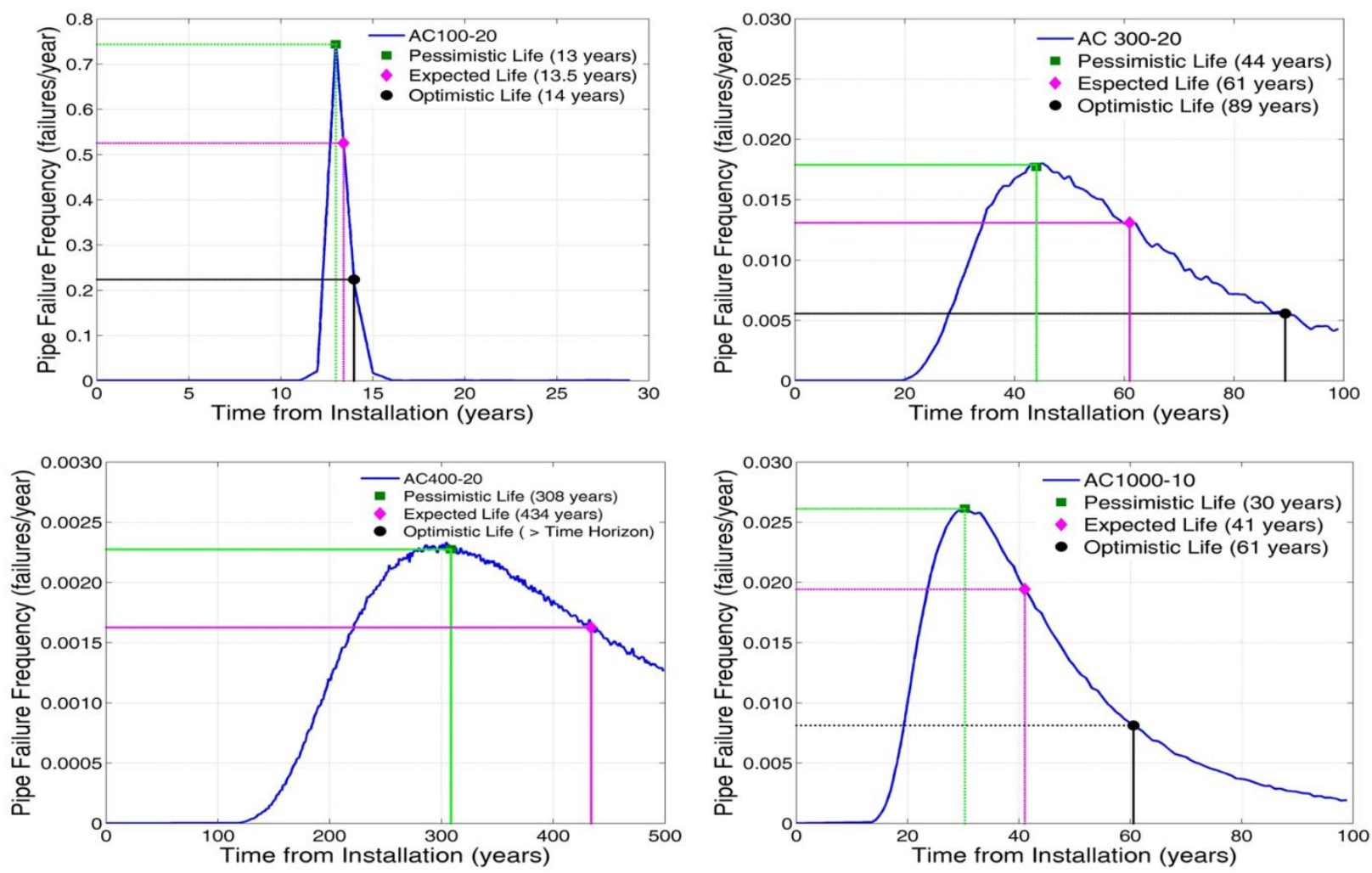

Fig. 6. Time to failure prediction of AC 100, 300, 400, and $1000 \mathrm{~mm}$ diameter water pipe subjected to the combined internal pressure and external loading using Monte Carlo simulation.

Table 5. Time to failure prediction of various diameter water AC pipes subjected to the combined internal pressure and external loading using Monte Carlo simulation.

\begin{tabular}{|c|c|c|c|c|c|c|c|c|c|c|}
\hline \multirow{2}{*}{ Attribute } & \multicolumn{10}{|c|}{ Diameter $(D, \mathrm{~mm})$} \\
\hline & 100 & 150 & 200 & 250 & 300 & 400 & 500 & 600 & 800 & 1000 \\
\hline Pessimistic life (years) & 12 & 21 & 12 & 11 & 44 & 300 & 77 & 14 & 12 & 30 \\
\hline Expected life (years) & 13 & 29 & 18 & 11 & 61 & 434 & 92 & 32 & 23 & 41 \\
\hline Optimistic life (years) & 13 & 42 & 32 & 12 & 89 & $>500$ & 116 & 54 & 57 & 61 \\
\hline $\begin{array}{l}\text { Maximum pipe failure } \\
\text { frequency (failures/year) }\end{array}$ & 0.743 & 0.037 & 0.047 & 0.629 & 0.018 & 0.0023 & 0.018 & 0.024 & 0.034 & 0.026 \\
\hline
\end{tabular}

\subsection{Observations and Prioritized Pipe Replacement Programs}

Table 6 gives a summary of the past pipe inspection data collected from the water utilities in the year 2015 provided information on AC pipe condition, pipe age, and the observed failure pattern during the forensic investigations. It is important to note that all the information was not always available because of the difficulties encountered in data collection followed by water utilities location, so direct comparison of the measured and simulated results was not always possible. It can be seen that buried pipes were subjected to 
internal pressure and pressure transients due to surges, external earth loads, self-weight and pipe contents, movement in the surrounding soils. Bell splitting with blow out holes failures appear to be common in smaller diameter pipes $(<300 \mathrm{~mm})$. While the larger diameter pipes $(>300 \mathrm{~mm})$ experience longitudinal cracks due to high water pressure and moments of inertia. Other observed failure modes and the identified driving factors are summarized in Table 6.

Table 6. Field observation of various diameter water AC from the water utilities.

\begin{tabular}{|c|c|c|c|}
\hline $\begin{array}{l}\text { AC pipe } \\
\text { diameter } \\
(\mathrm{mm})\end{array}$ & Visualization of pipe condition & $\begin{array}{c}\text { Pipe Age } \\
\text { (years) }\end{array}$ & Remarks \\
\hline 100 & & 12 & $\begin{array}{l}\text { Bell splitting at } \\
\text { the top of pipe } \\
\text { with } \\
\text { circumferential } \\
\text { break }\end{array}$ \\
\hline 150 & & 14 & $\begin{array}{l}\text { Elongated } \\
\text { chain created } \\
\text { corrosion } \\
\text { pitting with } \\
\text { blow out at } \\
\text { the end of } \\
\text { pipe }\end{array}$ \\
\hline 300 & & 40 & $\begin{array}{l}\text { Longitudinal } \\
\text { fracture }\end{array}$ \\
\hline 400 & & 30 & $\begin{array}{l}\text { Good } \\
\text { condition }\end{array}$ \\
\hline
\end{tabular}

Comparing the failure rate for each pipe types by age given in Table 5, AC100-20 and AC300-20 had the highest failure rate for pipes between $0-30$ and 30-60 years, of 0.743 and 0.018 failures per year, respectively. As can be seen in Table 6 , the prediction compares well with the observed pipe of diameter 100,300 , and $400 \mathrm{~mm}$ data. Based on what the utility finds to be acceptable rate of failures, pipes surpassing that acceptable failure rate should be considered for replacement with highest priority going to those having the highest failure frequency. It was also observed that AC400-20 was the only pipe type in the pipe system that the failure years will occur in the next 100 years or more. Thus, it is recommended that 
AC400-20 pipes be used at the utility where ever possible. Based on the outcome of the simulations, two possibilities are suggested. With these AC100-20 and AC250-20 pipes if failure will cause major problems, they are needed to be replaced when the next maintenance is planned. Sooner replacement would be better in this case. If failure will not cause major problems, authorities need to consider when replacement should be done. This could mean even after failure could be a possibility with no serious consequences. For AC150-20, AC200-20 and AC800-15 pipes, the decision to intervene can be based on the economic lifetime analysis. They can be replaced when it is economical (cost-effective) to do so. Other remaining pipe diameters remain in good conditions and can be run in the main, it becomes less cost-effective should they replace the pipes with the knowledge provided, before the expected time of failure.

\section{Conclusions}

Research work performed at present study demonstrates the feasibility of using the Monte Carlo method to estimate AC pipe failure rates as buried water pipeline age. The simulation sampled failure times by repeatedly generating random numbers for degradation rate to obtain data of the time of failure in trials. Pipe lifetime was determined iteratively by calculating the physical limit state for each year of age until pipe failure occurs. Based on the analysis of the results of the comprehensive studies on various pipe sizes and pressure class ratings in Thailand, it is inevitable that all pipes will eventually fail, but the output from the simulation provides a number of failures recorded over time, which then allows the remaining life period to be estimated. To prevent unplanned failures and schedule future replacement activities for AC pipes, a systematic management methodology with three components is suggested, thus aiding in the prioritization of pipelines future restoration activities.

\section{Acknowledgments}

The authors acknowledge the support of Mahidol University. The authors also thank The Thai Metropolitan Water Works Authority, the Royal Irrigation Department, the International Water Pipe Company Limited, Department of Civil and Environmental Engineering, Mahidol University, and CSIRO Urban Water Research, Australia for their supporting in the experiments.

\section{References}

[1] National Academy of Sciences, Drinking Water and Health. Washington D.C.: National Academy Press, 1982.

[2] M. E. Flentje and R. J. Sweitzer, "Solution effects of water on cement and concrete pipe," J. $A W W A$, vol. 47, pp.1173-1182, 1955.

[3] AWWA, Dawn of the Replacement Era: Reinvesting in Drinking Water Infrastructure. Denver, CO: American Water Works Association Research Foundation, 2001.

[4] R. J. Scott, Water Main Renewal Study: Reticulation Water Mains 1857-1990. Melbourne Water, 1990.

[5] H. L. Olson, “Asbestos in potable-water supplies," J. $A W W A$, vol. 66, no. 9, pp. 515-518, 1974.

[6] Y. Kleiner and B. Rajani, "Comprehensive review of structural deterioration of water mains: Statistical models," Urban Water, vol. 3, no. 3, pp. 131-150, 2001.

[7] Z. Liu and Y. Kleiner, "State of the art review of inspection technologies for condition assessment of water pipes," Measurement, vol. 46, pp. 1-15, 2013.

[8] A. Singh and S. Adachi, "Bathtub curves and pipe prioritization based on failure rate," Built Environment Project and Asset Management, vol. 3, no. 1, pp. 105-122, 2013.

[9] K. Pietrucha-Urbanik, "Failure analysis and assessment on the exemplary water supply network," Engineering Failure Analysis, vol. 57, pp. 137-142, 2015.

[10] A. M. Al-Adeeb and M. A. Matti, "Leaching corrosion of asbestos cement pipes," Int J Cement Composites and Lightweight Conc, vol. 6, no. 4, pp. 233-240. 1984.

[11] M. A. Matti and A. M. Al-Adeeb, "Sulphate attack on asbestos cement pipes," Int J Cement Composites and Lightweight Conc, vol. 7 no. 3, pp. 169-176, 1985.

[12] Y. Hu and D. W. Hubble, "Factors contributing to the failure of asbestos cement water mains," Canadian J Civ Eng, vol. 34 no. 5, pp. 608-621, 2007. 
[13] R. W. Buelow, J. R. Millette, E. F. McFarren, and J. M. Symons, "The behaviour of asbestos cement pipe under various water quality conditions: A progress report," J $A W W A$, vol. 72 no. 2, pp. 91-102, 1980.

[14] AWWARF and TZW, Internal Corrosion of Water Distribution Systems. AWWARF, 1996.

[15] ASTM, "Standard test methods for asbestos-cement pipe," ASTM C500-98, American Society for Testing and Materials, Philadelphia, PA, 1998.

[16] AWWA, "Standard for asbestos cement distribution pipe 4" through 16" for water and other liquids," AWWA C400-03, American Water Works Association Research Foundation, Denver, Co., 2003.

[17] M. Schock, and R.Buelow, "The behavior of asbestos-cement pipe under various water quality conditions: Part 2, theoretical considerations," J $A W W A$, vol.73 no.12, pp. 636-651, 1981.

[18] D. A. St. John, A. B. Poole, and I. Sims, Concrete Petrography: A Handbook of Investigative Techniques. London: Arnold, 1998.

[19] Colorado School of Mines. (1993). Chemical Equilibrium 2003. [Online]. Available: http://www.mines.edu/fs_home/epoeter/467/19SamplingPres/Water\%20Chem_Sampling_Presenta tion.pdf [Accessed: October 2011].

[20] B. Jarvis, “Asbestos-cement pipe corrosion—interim report," Western Australia, Australia: Customer Services Division, Water Corporation, 1998.

[21] J. M. Makar, R. Desnoyers, and S. E. McDonald, "Failure modes and mechanisms in gray cast iron pipes," presented at Underground Infrastructure Research, Waterloo, Ontario, June 10-13th, 2001.

[22] A. Borsoi, S. Collepardi, L. Coppola, R. Troli, and M. Collepardi, "Sulfate attack on blended Portland cement," ACI Special Publications, vol. 192, pp. 471-432, 2000.

[23] D. G. Ellis, G. Moore, and P. Ferguson, "Environmental corrosion testing of ductile iron water pipes," Corrosion and Prevention, vol. 98, pp. 61-68, 1998.

[24] P. Davis, D. De Silva, S. Gould, and S. Burn, "Condition assessment and failure prediction for asbestos cement sewer mains," in Proc. Pipes Wagga Wagga 2005, Wagga Wagga, Australia, 17-20th October, 2005.

[25] P. Davis, D. De Silva, D. Marlow, M. Moglia, S. Gould, and S. Burn, "Failure prediction and optimal scheduling of replacements in asbestos cement water pipes," JWater Supply Research and Tech-Aqua, vol. 57, no. 4, pp. 239-252, 2008.

[26] P. Davis, D. De Silva, S. Gould, "Improving asset management of water pipelines through understanding materials durability and failure," in Proc. OzWater 09, Melbourne, Australia, 16-18th March, AWA, 2009.

[27] W. Punurai, P. Davis, and S. Gould, "Prediction of asbestos cement water pipe ageing and replacement scheduling using Monte Carlo simulation," in Proc. Structural Faults + Repairs $2014 \& 15$ th European Bridge Conference, Imperial College, London, UK, 2014.

[28] A. Katz, "Effect of fiber modulus of elasticity on the long term properties of micro-fiber reinforced cementitious composites," Cem and Conc Composites, vol. 18, pp. 389-399, 1996.

[29] Standards Australia, "Standards Australia for buried flexible pipelines part 1: Structural Design," Standards Australia, AS 2566.1, Sydney, Australia, 1998.

[30] J. Olliff and S. Rolfe, "Condition assessment: the essential basis for the best rehabilitation practice," in Proceeding of NO-DIG 2002, Copenhagen, Denmark. 